
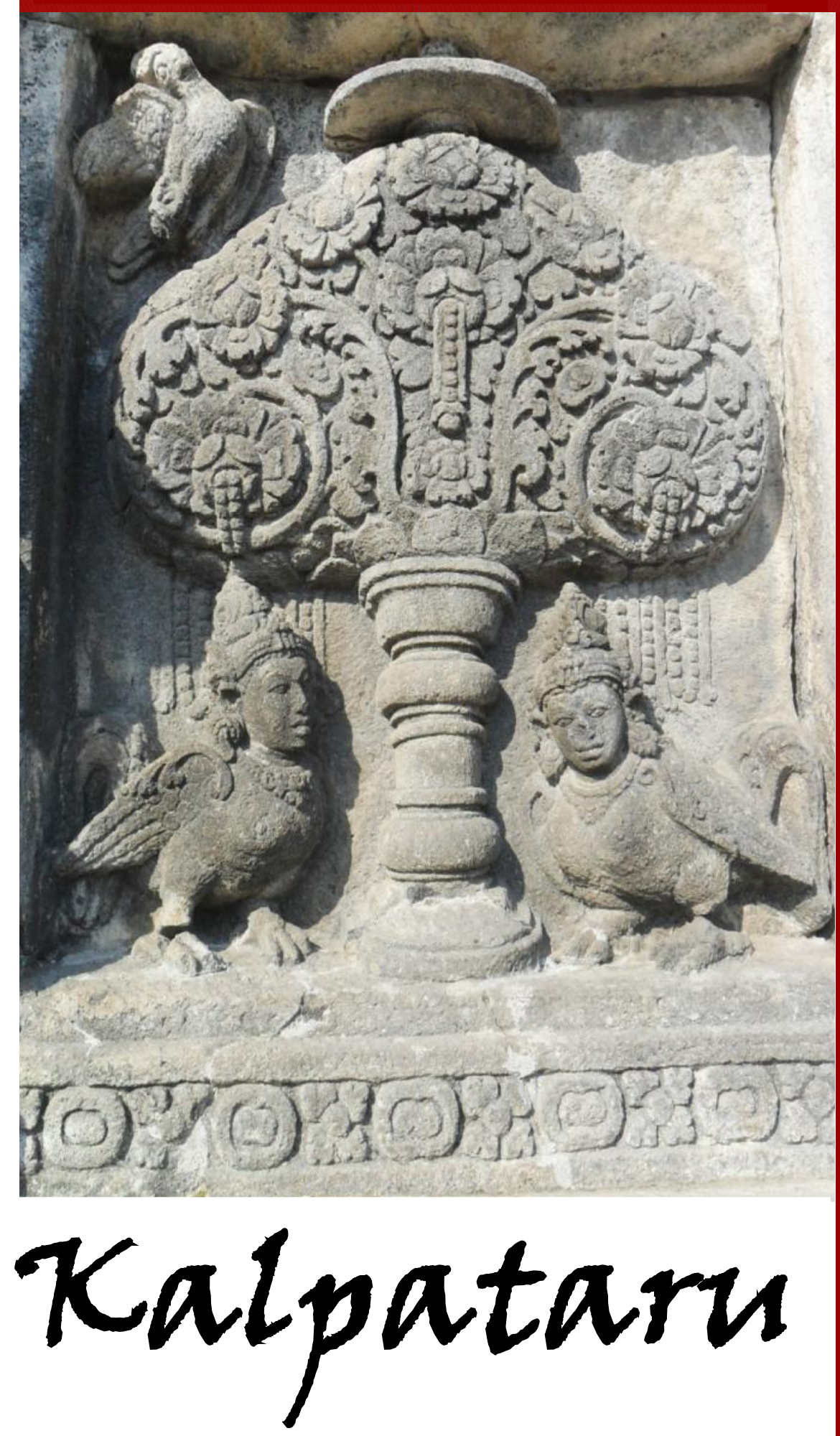

JURNAL SEJARAH DAN PEMBELAJARAN SEJARAH

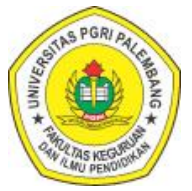

Program Studi Pendidikan Sejarah Jurusan Pendidikan IPS

Fakultas Keguruan dan IImu Pendidikan Universitas Persatuan Guru Republik Indonesia Palembang
Kajian Tata Ruang Lukisan Dinding Pada Batu Balai di Desa Tegur Wangi Lama Kota Pagaralam Sebagai Sumber Pembelajaran Sejarah

Muhammad Randi Saputra, H. Rudi Asri

Nilai Sejarah Toponim di Kecamatan Bukit Kecil Kota Palembang Sebagai Sumber Pembelajaran Sejarah di SMP Negeri 33 Palembang

Dedi Berianto

Upaya Meningkatkan Kualitas Pembelajaran Sejarah Melalui Penerapan Outdoor Learning Berbasis Inkuiri di SMA Muhammadiyah 1 Palembang

Arman, Fatmah

Senjang: Sejarah Tradisi Lisan Masyarakat Musi Banyuasin

Brian Apriadi, Eva Dina Chairunisa

Peningkatan Hasil Belajar dan Aktifitas Siswa Melalui Model Pembelajaran Discovery Learning di SMA Negeri 8 Palembang

Sri Mulyati, Nurhayati Dina, Apriana

Jenis-Jenis Peninggalan Megalit di Desa Tanjung Aro Sebagai Sumber Pembelajaran Sejarah di Kelas X SMA Muhammadiyah 3 Palembang Tahun Ajaran 2017/2018

Lita Sepriani

Persepsi Siswa Terhadap Penggunaan Media Film Dokumenter Materi Kehidupan Manusia Purba Pada Mata Pelajaran Sejarah di SMK Negeri 6 Palembang M. Edo Nuryana

Sejarah Tulung Selapan Sebagai Sumber Penulisan Sejarah Lokal Ogan Komering Ilir

Muhamad Idris

Pengaruh Model Pembelajaran Explicit Instruction Terhadap Hasil Belajar Siswa Pada Mata Pelajaran Sejarah di Sekolah Menengah Atas Negeri 1 Gelumbang Ramoni Handayani

Pengaruh Penggunaan Media Film Dokumenter Terhadap Hasil Belajar Siswa Pada Mata Pelajaran Sejarah di Sekolah Menengah Atas Sriguna Palembang Vina Pratiwi 


\section{Kalpataru}

Jurnal Sejarah dan Pembelajaran Sejarah

Volume 4, Nomor 2, Desember 2018

Penanggung Jawab

Dr. Dessy Wardiah, M.Pd.

Ketua Dewan Redaksi

Drs. Sukardi, M.Pd.

\section{Penyunting Pelaksana}

Muhamad Idris, M.Pd.

Eva Dina Chairunisa, M.Pd.

Jeki Sepriady, S.Pd.

Dr. Tahrun, M.Pd.

Drs. Supriyanto, M.Hum.

Dra. Retno Purwati, M.Hum.

Dr. Nor Huda Ali, M.Ag., M.A.

Budi Agung Sudarman, S.S., M.Pd.

Dr. Purmansyah, M.A.

\section{Penyunting Ahli}

(Universitas PGRI Palembang)

(Universitas Sriwijaya Palembang)

(Balai Arkeologi Sumatera Selatan)

(Masyarakat Sejarawan Indonesia Sumsel)

(Balai Bahasa Provinsi Sumatera Selatan)

(Universitas Muhammadiyah Palembang)

\section{Alamat Redaksi}

Program Studi Pendidikan Sejarah

Jurusan Pendidikan IImu Pengetahuan Sosial

Fakultas Keguruan dan IImu Pendidikan Universitas PGRI Palembang

Telp. 0711-510043

Email: jurnalkalpatarusejarah@gmail.com

Website: https://jurnal.univpgri-palembang.ac.id/index.php/Kalpa 


\section{Kalpataru}

\author{
JURNAL SEJARAH DAN
}

PEMBELAJARAN SEJARAH

Terbit dua kali setahun pada Juli dan Desember

Diterbitkan oleh:

Program Studi Pendidikan Sejarah Jurusan Pendidikan IPS

Fakultas Keguruan dan IImu Pendidikan Universitas PGRI Palembang

\section{Gambar Cover: \\ Pohon Kalpataru \\ Candi Prambanan}

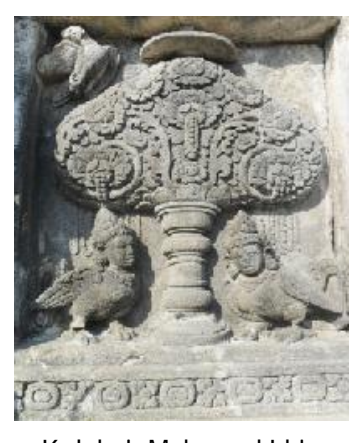

Koleksi: Muhamad Idris

\section{DAFTAR ISI}

Kajian Tata Ruang Lukisan Dinding Pada Batu Balai di Desa Tegur Wangi Lama Kota Pagaralam Sebagai Sumber Pembelajaran Sejarah

Muhammad Randi Saputra, H. Rudi Asri. $.89-98$

Nilai Sejarah Toponim di Kecamatan Bukit Kecil Kota Palembang Sebagai Sumber Pembelajaran Sejarah di SMP Negeri 33 Palembang

Dedi Berianto. 99-110

Upaya Meningkatkan Kualitas Pembelajaran Sejarah Melalui Penerapan Outdoor Learning Berbasis Inkuiri di SMA Muhammadiyah 1 Palembang

Arman, Fatmah.

Senjang: Sejarah Tradisi Lisan Masyarakat Musi Banyuasin

Brian Apriadi, Eva Dina Chairunisa

Peningkatan Hasil Belajar dan Aktifitas Siswa Melalui Model Pembelajaran Discovery Learning di SMA Negeri 8 Palembang

Sri Mulyati, Nurhayati Dina, Apriana.

Jenis-Jenis Peninggalan Megalit di Desa Tanjung Aro

Sebagai Sumber Pembelajaran Sejarah di Kelas X SMA

Muhammadiyah 3 Palembang Tahun Ajaran 2017/2018

Lita Sepriani..

Persepsi Siswa Terhadap Penggunaan Media Film Dokumenter Materi Kehidupan Manusia Purba Pada Mata Pelajaran Sejarah di SMK Negeri 6 Palembang M. Edo Nuryana.

Sejarah Tulung Selapan Sebagai Sumber Penulisan Sejarah Lokal Ogan Komering Ilir Muhamad Idris. $146-153$

Pengaruh Model Pembelajaran Explicit Instruction Terhadap Hasil Belajar Siswa Pada Mata Pelajaran Sejarah di Sekolah Menengah Atas Negeri 1 Gelumbang

Ramoni Handayani. 154-161

Pengaruh Penggunaan Media Film Dokumenter Terhadap Hasil Belajar Siswa Pada Mata Pelajaran Sejarah di Sekolah Menengah Atas Sriguna Palembang

Vina Pratiwi. $162-169$ 


\title{
JENIS-JENIS PENINGGALAN MEGALIT DI DESA TANJUNG ARO SEBAGAI SUMBER PEMBELAJARAN SEJARAH DI KELAS X SMA MUHAMMADIYAH 3 PALEMBANG TAHUN AJARAN 2017/2018
}

\author{
Lita Sepriani \\ Mahasiswa Program Studi Pendidikan Sejarah FKIP Universitas PGRI Palembang
}

\begin{abstract}
ABSTRAK
Permasalahan penelitian adalah bagaimanakah jenis-jenis peninggalan megalit di desa Tanjung Aro dapat dimanfaatkan sebagai sumber pembelajaran sejarah di SMA Muhammadiyah 3 Palembang. Tujuan penelitian adalah untuk mengetahui jenis-jenis peninggalan megalit yang dapat dimanfaatkan sebagai sumber pembelajaran sejarah di SMA Muhammadiyah 3 Palembang. Metode yang digunakan dalam penelitian adalah metode deskriptif kualitatif. Teknik pengumpulan data yang digunakan adalah dokumentasi, observasi dan wawancara. Hasil penelitian dapat disimpulkan: jenis-jenis peninggalan megalit di desa Tanjung Aro yaitu arca manusia dililit ular yang mengandung nilai moral kehidupan manusia, batu dolmen berfungsi untuk meletakkan sesajian kepada roh nenek moyang, kubur batu berfungsi sebagai tempat meletakkan mayat yang telah meninggal, lumpang batu digunakan untuk menumbuk padi-padian dan persebaran batu megalit yang terdapat di tengah persawahan milik warga. Jenis-jenis peninggalan megalit dapat dijadikan sebagai sumber pembelajaran sejarah kelas $X$ di SMA Muhammadiyah 3 Palembang, dalam membantu peserta didik lebih mengenal jenis-jenis peninggalan megalit, sehingga dapat memotivasi memelihara hasil kebudayaan yang ada di Sumatera Selatan khususnya di desa Tanjung Aro.
\end{abstract}

Kata Kunci: Jenis-Jenis Peninggalan Megalit, Sumber Pembelajaran Sejarah.

\section{A. PENDAHULUAN}

Kota Pagaralam disebut dengan kota Besemah, Besemah sendiri adalah nama tanah, nama daerah, nama etnik, nama bahasa, nama adat, dan nama kebudayaan provinsi Sumatera Selatan. Besemah berasal dari kata dasar "Semah" yang berarti air (sungai) yang ada ikan semah hidup di sungai-sungai atau danaudanaunya (Tim, 2014:11). Dahulu Besemah mencakup suatu wilayah yang luas, menjadi terpecah-pecah karena dikecilkan oleh Belanda. Sehingga tampaklah oleh kita sekarang kalau Besemah hanya sebatas Pagaralam. Namun ada yang menarik, bila keturunan Besemah ini ingin bersatu kembali maka sudah tersedia jalan, yakni adanya persamaan bahasa, adat, dan seperasaan, terbukti masih adanya bahasa Besemah meskipun orang tersebut tidak di Pagaralam. Contoh beberapa daerah yang menggunakan bahasa Besemah, antara lain: Pagaralam, Lahat, Palas Pasemah (Lampung), Kota Agung, Padang Guci, dan daerah lainnya (Puspa, 2013:16).

Zaman prasejarah Indonesia meninggalkan budaya material yang cukup berarti bagi pemahaman cara berpikir nenek moyang bangsa Indonesia. Benda-benda material itu berupa dari perunggu. Dalam studi prasejarah, kedua jenis material tersebut diproduksi pada zaman megalitikum dan zaman perunggu (Dongson). Bangunan-bangunan batu terdiri dari batu berdiri (menhir), Peti Batu, Sarkopagus, Arca, Punden Berundak, dan Batu Bergambar. Sedangkan benda-benda perunggu terdiri dari Kapak Perunggu, Kapak Sepatu, Patung-Patung, Nekara atau Genderang Perunggu peninggalanpeninggalan purba tersebut merupakan ekspresi pengamalan dan pemikiran bangsa Indonesia pada zamannya, yang sekarang ini masih dapat kita amati secara nyata. Benda-benda prasejarah itu mengandung isyarat-isyarat bahasa pikiran nenek moyang Indonesia yang harus kita baca sesuai dengan makna semula (Sumardjo, 


\section{Kalpataru, Volume 4, Nomor 2, Desember 2018 (129-134)}

2002:111).

Bangunan megalitik terdapat di bagian Selatan pulau tersebut, yaitu di dataran tinggi Tanah Besemah. Daerah ini terletak di antara Bukit Barisan dan Pegunungan Gumay, di lereng gunung Dempo (3173 mdpl). Peninggalan megalitik yang terdapat di Besemah terutama berupa Menhir, Dolmen, Peti Kubur, Batu Lesung, serta patung-patung batu yang bergaya statis dan dinamis. Temuan-temuan megalitik yang paling menarik di Tanah Besemah adalah arca-arca batu yang dinyatakan oleh Von Heine Gelden bergaya "dinamis" dan "statis". Arca-arca ini juga menggambarkan bentuk-bentuk binatang, seperti gajah, harimau, dan monyet (Bedur, 2009:20-25). Bangunan megalitik banyak ditemukan di bagian Selatan dataran tinggi Tanah Basemah. Daerah ini mempunyai peninggalan megalitik yang banyak peninggalan tersebut diantaranya yaitu Menhir, Dolmen, Peti Kubur, Batu Lesung, serta patung-patung batu yang bergaya statis dan dinamis.

Kebudayaan megalitik di Indonesia mempunyai persebaran yang amat luas. Termasuk diantaranya kebudayaan megalitik yang terbesar di dataran tinggi Besemah, provinsi Sumatera Selatan. Situssitus megalitik di daratan tinggi Besemah meliputi daerah yang luasnya sekitar 80 $\mathrm{km}^{2}$. Situs-situs megalitik tersebar di daratan tinggi seperti di puncak gunung, di lereng dan di lembah. Pada umumnya situs-situs megalitik berada di ketinggian 500 mdpl, karena terletak di dataran tinggi maka daerah ini mempunyai curah hujan yang tinggi sepanjang tahun yang terletak di desa Tanjung Aro.

Di daerah Pagaralam tepatnya di situs megalit Tanjung Aro yang termasuk dalam kecamatan Pagaralam Utara. Temuan megalitik yang terdapat dalam kawasan ini yaitu: arca megalit manusia dililit ular, batu lumpang, kubur batu, dolmen, dan sebaran batu-batu megalit. Kebudayaan di situs ini yang menarik bahwa hasil dari peninggalan-peninglan di situs ini yaitu pada masa prasejarah zaman megalitikum atau juga disebut zaman batu besar. Karna hal tersebut peneliti tertarik mengambil judul yang berjudul "Jenis-Jenis Peninggalan Megalit di Desa Tanjung Aro Sebagai Sumber Pembelajaran Sejarah".

Adapun rumusan masalah pada penelitian ini adalah bagaimanakah jenisjenis peninggalan megalit di desa Tanjung Aro yang dapat dimanfaatkan sebagai sumber pembelajaran sejarah di sekolah menengah atas?

\section{B. METODE PENELITIAN}

Metode yang digunakan dalam penelitian ini adalah deskriptif kualitatif.

Objek dan Informan Penelitian. Objek dalam penelitian ini adalah jenis-jenis peninggalan megalit di desa Tanjung Aro yang dapat dijadikan sebagai sumber pembelajaran sejarah, yang ada di kelurahan Kuripan Babas, kecamatan Pagaralam Utara kota Pagaralam.

Alasan memilih objek penelitian ini karena terdapat nilai jenis-jenis peninggalan megalit yang menurut penulis perlu dikembangkan dalam sumber pembelajaran di sekolah menengah atas. Lokasi penelitian sumber pembelajaran sejarah yaitu di SMA Muhamadiyah 3 Palembang yang beralamat di Jl. Masa Jaya, 13 Ulu, Seberang Ulu II kota Palembang Sumatera Selatan 30116.

Informan penelitian dilakukan dengan pengurus peninggalan sejarah yaitu bapak Rahmat, kemudian guru sejarah SMA Muhamadiyah 3 Palembang yaitu bapak Amar AM, S.H., S.Sos. Untuk mencari informasi tentang valid atau tidaknya data tersebut untuk dijadikan sebagai sumber pembelajaran sejarah.

Penelitian deskriptif kualitatif merupakan jenis penelitian yang temuantemuannya tidak diperoleh dari statistik atau bentuk hitungan lainnya yang bersifat deskriptif dan cenderung menggunakan analisis dengan pendekatan induktif. Metode penelitian kualitatif sering disebut dengan 
metode penelitian naturalistik karena penelitiannya dilakukan secara kondisi yang alamiah karena pada awalnya metode ini lebih banyak digunakan untuk penelitian bidang antropologi budaya, dan juga metode deskriptif kualitatif diuraikan dengan katakata menurut peneliti dan akan disimpulkan oleh peneliti.

Metode deskriptif kualitatif adalah suatu metode dalam meneliti status sekelompok manusia, suatu objek, suatu set kondisi, suatu sistem pemikiran, ataupun suatu kelas peristiwa pada masa sekarang. Tujuan dari penelitian deskriptif kualitatif ini adalah untuk membuat deskripsi, gambaran atau lukisan secara sistematis, faktual dan akurat mengenai fakta-fakta, sifat-sifat serta hubungan antar fenomena yang diselidiki. Berdasarkan pada beberapa pendapat tersebut memberikan makna bahwa penelitian deskriptif kualitatif adalah penelitian dengan tujuan untuk menggambarkan suatu peristiwa pada saat sekarang yang nampak dalam suatu situasi.

Jadi metode penelitian deskriptif kualitatif adalah, data yang diperoleh dikumpulkan, disusun, dijelaskan, dan dianalisis untuk menetapkan kesimpulan. Hal ini untuk memperoleh gambaran yang jelas sehingga tujuan penelitian tercapai seperti yang diharapkan.

Alasan peneliti menggunakan metode deskriptif kualitatif, karena penelitian ini ingin mendeskripsikan dan mengungkap tentang jenis-jenis peninggalan megalit di desa Tanjung Aro sebagai sumber pembelajaran sejarah pada siswa SMA Muhammadiyah 3 Palembang. Deskriptif kualitatif diuraikan dengan kata-kata menurut peneliti dan akan disimpulkan oleh peneliti.

\section{HASIL DAN PEMBAHASAN}

Arca megalit yaitu pahatan dalam bentuk tokoh manusia atau binatang. Arca megalit di Besemah mempunyai ciri khas yang tidak ditemukan pada arca megalitik yang lain di Indonesia. Kekhususan tersebut terletak pada gerak dan irama dari pahatan- pahatan seluruh bagian badannya, yang begitu hidup dengan gerak bebas, yang tidak terkait oleh aturan seperti yang dianut pada pembuatan arca statis. Dari gerak dan irama dalam pemahatan tangan, badan, kaki dan lain-lain menunjukkan bahwa arca megalitik Besemah tampak begitu dinamis.

Adapun ciri-ciri umum dari sekian banyak temuan megalit tanah Besemah khususnya di kota Pagaralam, yaitu sebagai berikut:

1. Badan dan anggota badan digambarkan dalam bentuk tambun.

2. Bibir tebal, hidung pesek dan mata bulat.

3. Bagian kepala lebih kedepan dari bagian tubuhnya sehingga seolah-olah arcanya sedang membungkuk.

4. Arca ada yang dipahatkan mengapit kerbau atau gajah.

5. Di bagian punggung ada nekara perunggu, anak dan ada terselip sebuah belati tipe Dongson (Disbudpar Pagaralam, 2016:3).

Arca megalitik biasanya merupakan personifikasi dari nenek moyang, arca ini dipergunakan dalam kaitannya dengan upacara (pemujaan) untuk usaha mendekatkan diri dengan arwah nenek moyang. Arca megalitik Besemah mempunyai peranan dan fungsi yang sangat penting. Pahatan-pahatan dalam bentuk manusia dan binatang itu berkaitan dengan maksud-maksud religius disamping dipergunakan sebagai simbol-simbol. Budaya material Besemah memiliki ekspresi seni yang bernilai tinggi.

Arca menhir yang merupakan tinggalan yang bersifat universal itu, pada awalnya dibuat sebagai suatu penggambaraan dari orang yang telah meninggal. Arca ini ada yang ditempatkan pada kubur, sebagai sarana untuk pemujaan agar arwah selamat di alam arwah, dan yang ditinggalkan juga memperoleh keselamatan. Arca yang merupakan identifikasi dari seorang tokoh ataupun pimpinan oleh ahli warisan 
kemudian dipuja-puja untuk memperoleh berkah.

\section{Pembahasan}

\section{Jenis-Jenis Peninggalan Megalit di Desa Tanjung Aro}

Jenis-jenis peninggalan megalit di desa Tanjung Aro kota Pagaralam merupakan materi yang dapat diajarkan pada pembelajaran sejarah di SMA Muhammadiyah 3 Palembang, secara umum pembelajaran sejarah di SMA Muhammadiyah 3 Palembang yaitu mereka sudah menggunakan kurikulum 2013. Buku yang digunakan juga sesuai dengan kurikulum 2013, di SMA Muhammadiyah 3 Palembang selalu memanfaatkan sumber untuk menunjang sistem pembelajaran sejarah di kelas seperti buku dari dinas dan Iks, dan juga media gambar. Di SMA Muhammadiyah 3 Palembang juga hanya kelas $X$ yang menggunakan kurikulum 2013 sedangkan yang lain belum menggunakan kurikulum 2013 ini. Buku yang digunakan di SMA ini yaitu buku sejarah Indonesia (wajib) yang diterbitkan oleh Erlangga.

Menurut Amar AM, S.H., S.Sos. selaku guru sejarah dan kepala tata usaha SMA Muhammdiyah 3 Palembang dalam pelaksanaan pembelajaran sejarah beliau sudah menggunakan sumber pembelajaran dengan baik dalam proses pembelajaran di kelas, metode yang yang digunakan juga tidak lepas dari menerangkan, memberikan tugas, ceramah, serta tanya jawab, karna keterbatasan sarana dan prasarana yang ada sekolah mereka hanya menggunakan media-media sederhana seperti media gambar berupa karton.

Menurut beliau kendala yang didapat ketika melalukan proses pembelajaran di kelas yaitu seharusnya kurikulum 2013 sudah menggunakan sistem pembelajarannya elektronik seperti komputer dan infocus tetapi karna fasilitas yang ada disekolah tidak memenuhi maka mereka mengajar hanya dengan menggukan media-media yang sederhana dan mudah dipahami oleh siswa, selain itu juga sering diadakannya pembagian kelompok diskusi aktif agar para siswa tertarik dan mau mengeluarkan argumen mereka tentang materi yang sedah dibahas, sejauh ini penggunaan model pembelajaran seperti ini dapat membatu siswa untuk aktif dalam kelas. Dan dapat juga menghindari adanya siswa yang mengantuk dan tidur dalam kelas.

Sistem belajar mengajar dikelas akan terlaksana dengan baik apabila seorang guru itu sendiri memahami materi pembelajaran sebelum disampaikan kepada siswa, selain itu adanya tingkat kreatifitas agar dapat menghidupkan suasana kelas yang tidak aktif menjadi aktif, yang tidak tertarik menjadi tertarik.

Menurut Amar AM, S.H., S.Sos. jenisjenis peninggalan megalit di desa Tanjung Aro kota Pagaralam layak dijadikan sebagai sumber pembelajaran sejarah di Sekolah Menegah Atas Muhammdiyah 3 Palembang karna siswa harus lebih memahami dan mengetahui tentang peninggalan megalitmegalit yang ada di kota Pagaralam, khususnya tentang hasil jenis-jenis megalit di desa Tanjung Aro kecamatan Pagaralam Utara kota Pagaralam. Berdasarkan hasil wawancara dengan beliau pada hari Selasa 20 November 2018 pada pukul 11:27 Wib mengenai jenis-jenis peninggalan megalit di desa Tanjung Aro kota Pagaralam sebagai sumber pembelajaran sejarah di sekolah menengah atas dapat dijadikan sebagai materi pembelajaran sejarah kelas $X$ yang berkaitan dengan $\mathrm{KI} 2$ dan KD 2.1 jenis-jenis peninggalan megalit di desa Tanjung Aro sebagai sumber pembelajaran sejarah di kelas $\mathrm{X}$.

Menurut Amar AM, S.H., S.Sos selaku guru sejarah di SMA Muhammadiyah 3 Palembang sedikit banyaknya beliau sudah mengetahui mengenai jenis-jenis peninggalan megalit pada masa prasejarah yang berada di kota Pagaralam dan dapat dikembangkan dalam proses pembelajaran kelas $X$ di SMA Muhammadiyah 3 


\section{Kalpataru, Volume 4, Nomor 2, Desember 2018 (129-134)}

Palembang. Menurut beliau juga judul penulis sudah bisa dijadikan sebagai sumber pembelajaran sejarah karena judulnya sudah terfokus pada satu temuan saja dan akan menjadi daya tarik pada siswa, dikarenakan sebagian besar siswa mengetahui kota Pagaralam yaitu kota yang terkenal akan keindahannya.

Kurikulum yang digunakan di SMA Muhammadiyah 3 palembang ini yaitu kurikulum 2013, dimana pada kurikulum 2013 pemerintah menetapkan kompetensi inti (KI) dan kompetensi dasar (KD), sedangkan guru dituntut untuk mengembangkan silabus dan indikator pencapaian kompetensi. Jadi awalnya penulis mencari silabus untuk dikembangkan sesuai dengan ketetapan peraturan pada kurikulum 2013, dan penulis mencari kompetensi inti (KI) dan kompetensi dasar (KD) untuk disesusaikan dengan penelitian penulis, selain itu penulis juga membuat bahan ajar yang berhubungan dengan penelitian penulis yaitu jenis-jenis peninggalan megalit di desa Tanjung Aro kota Pagaralam sebagai sumber pembelajaran sejarah di sekolah menengah atas kemudian dimasukkan kedalam rencana pelaksanaan pembelajaran (RPP) agar dapat dijadikan sebagai sumber pembelajaran sejarah dan dapat diajarkan di peserta didik.

Berdasarkan hasil penelitian yang penulis lakukan di desa Tanjung Aro kota Pagaralam untuk mendapatkan hasil penelitian yang akan dijadikan sebagai sumber pembelajaran di SMA Muhammadiyah 3 Palembang bahwa jenisjenis peninggalan megalit di desa Tanjung Aro kota Pagaralam sebagai sumber pembelajaran sejarah dapat dijadikan sebagai sumber pembelajaran sejarah di SMA Muhammadiyah 3 Palembang yang dapat dikategorikan dalam $\mathrm{KI} 2$ yaitu Menghayati dan mengamalkan perilaku jujur, disiplin, tanggung jawab, peduli (gotong royong, kerjasama, toleran, damai), santun, responsif, dan pro-aktif dan menunjukkan sikap sebagai bagian dari solusi atas berbagai permasalahan dalam berinteraksi secara efektif dengan lingkungan sosial dan alam serta dalam menempatkan diri sebagai cerminan bangsa dalam pergaulan dunia, dan KD 2.1 yaitu Menunjukkan sikap tanggung jawab, peduli terhadap berbagai hasil budaya zaman praaksara, Hindu-Buddha dan Islam.

Jadi dapat disimpulkan bahwa judul penulis jenis-jenis peninggalan megalit di desa Tanjung Aro kota Pagaralam sebagai sumber pembelajaran sejarah di sekolah menengah atas layak dan dapat dijadikan serta dikembangkan sebagai sumber atau bahan ajar pembelajaran sejarah untuk kelas $X$ di SMA Muhammadiyah 3 Palembang.

\section{SIMPULAN}

Berdasarkan hasil penelitian mengenai jenis-jenis peninggalan megalit di desa Tanjung Aro sebagai sumber pembelajaran sejarah di sekolah menengah atas, jadi penulis dapat mengambil kesimpulan bahwa di situs Tanjung Aro ini terdapat peninggalan-peninggalan megalit yang terdiri dari 1 lumpang batu, 1 dolmen, 1 arca yaitu arca manusia dililit Ular, serta 2 kubur batu, dan persebaran batu megalit, peninggalan-peninggalan di situs Tanjung Aro ini sudah termasuk dalam perlindungan dan pengawasan Balai Perlindungan Cagar Budaya Jambi (BPCB Jambi).

Kebudayaan manusia prasejarah itu sendiri dapat dilihat dari peninggalanpeninggalan megalit di situs Tanjung Aro yaitu jika dilihat dari Lumpang Batu kebudayaan yang dapat diambil yaitu kebudayaan pertanian mereka sudah mengenal bercocok tanam, kemudian jika dilihat dari dolmen, dan kubur batu kebudayaan yang dapat diambil yaitu kebudayaan religi karna fungsi dari dolmen yaitu tempat meletakkan sesaji kepada roh nenek moyang dan kubur batu merupakan lambang penghormatan terhadap roh nenek moyang, sedangkan jika dilihat dari arca 
manusia dililit ular kebudayaan yang dapat diambil yaitu pentingnya nilai moral dalam kehidupan manusia selain itu kebudayaan manusia prasejarah di desa Tanjung Aro kota Pagaralam juga dapat dijadikan sebagai sumber pembelajaran sejarah di sekolah menengah atas yang akan diterapkan di kelas X SMA Muhammadiyah 3 Palembang.

\section{DAFTAR PUSTAKA}

Bedur, Marzuki. 2009. Sejarah Besemah dari Zaman Megalitikum, Lampik Mpat Mardike Duwe, Sindang Mardike ke Kota Perjuangan. Pagaralam: Pemerintah Kota Pagaralam.

Dinas Kebudayaan dan Pariwsata Kota Pagaralam. (n.d). Pagar Alam Beauty Of South Sumatera. Pagaralam: Pemerintah Kota Pagaralam Dinas Kebudayaan dan Pariwsata.

Puspa, Eti. 2013. Sastra Basemah Bagian Dari "Sastra Melayu Lama". Bandung, Jawa Barat.

Sumardjo, Jacob. 2002. Arkeologi Budaya Indonesia (Pelacakan HermeneutisHistoris Terhadap Artefak-Artefak Kebudayaan). Yogyakarta: Qalam.

Tim. 2014. Sastra Tutur Sumatera Selatan Besemah. Palembang: Pemerintah Provinsi Sumatera Selatan Dinas Pendidikan. 


\section{KETENTUAN PENULISAN ARTIKEL JURNAL KALPATARU}

1. Naskah berbahasa Indonesia yang disempurnakan bertemakan kesejarah yang meliputi hasil penelitian sejarah, pengajaran sejarah dan penelitian kebudayaan.

2. Naskah harus asli dan belum pernah dimuat dalam media lain. Naskah dapat berupa hasil penelitian/artikel kajian konseptual yang ditulis oleh perorangan dan atau kelompok.

3. Naskah ditulis dengan cara-cara yang sesuai dengan ketentuan penulisan artikel ilmiah menggunakan bahasa Indonesia yang baku, berupa ketikan, beserta soft file dalam CD-RW atau dengan mengirimkan email pada redaksi jurnal Kalpataru dengan alamat jurnalkalpatarusejarah@gmail.com, spasi tunggal, jenis huruf arial narrow ukuran 12, dengan panjang naskah antara 8-15 halaman pada kertas A4.

4. Artikel hasil penelitian memuat:

JUDUL

Nama Penulis

Abstrak

A. PENDAHULUAN

B. METODE PENELITIAN

C. HASIL DAN PEMBAHASAN

D. SIMPULAN

DAFTAR PUSTAKA
: XXX (HURUF KAPITAL)

: (disertai jabatan, institusi, dan email)

: (Bahasa Indonesia yang memuat 100-200 kata diikuti kata kunci, dengan jenis huruf arrial narrow dan ukuran huruf 11 serta dicetak miring).

: (memuat latar belakang masalah, tinjauan pustaka secara ringkas, masalah penelitian, dan tujuan penelitian).

: (berisi simpulan).

: (berisi pustaka yang dirujuk dalam uraian naskah).

5. Artikel Kajian Konseptual memuat:

\section{JUDUL \\ Nama Penulis \\ Abstrak \\ PENDAHULUAN \\ Sub Judul \\ Simpulan \\ DAFTAR PUSTAKA}

: XXX (HURUF KAPITAL)

: (disertai jabatan, institusi, dan email)

: (Bahasa Indonesia yang memuat 100-200 kata diikuti kata kunci, dengan jenis huruf arrial narrow dan ukuran huruf 11 serta dicetak miring.

: (memuat latar belakang masalah, tinjauan pustaka secara ringkas, masalah penelitian, dan tujuan penelitian).

: Sesuai dengan kebutuhan (tanpa numbering).

: (berisi simpulan dan saran).

6. Referensi sumber dalam teks artikel ditulis dengan menggunakan side note, contoh (Jalaludin, 1991:79); sementara penulisan daftar pustaka disusun dengan ketentuan. Nama pengarang. Tahun terbit. Judul (dicetak miring). Kota terbit: Nama Penerbit. Contoh: Koentjaraningrat. 2010. Manusia dan Kebudayaan di Indonesia. Jakarta: Djambatan. Daftar pustaka hanya memuat pustaka/sumber yang dirujuk dalam uraian dan disusun menurut abjad tanpa nomor urut.

7. Naskah yang dimuat akan disunting kembali oleh redaksi tanpa mengubah isinya.

8. Naskah yang ditolak (tidak bisa dimuat) akan dikirim kembali ke penulis dengan pemberitahuan tertulis dari redaksi atau melalui email.

9. Penulis yang naskahnya dimuat akan mendapat 1 (satu) majalah nomor yang bersangkutan.

10. Kontak person: Muhamad Idris (081271498618); Eva Dina Chairunisa (082281267851); Jeki Sepriady (085269261780). 